\title{
Lysosomal Adaptation: How the Lysosome Responds to External Cues
}

\author{
Carmine Settembre ${ }^{1,2,3,4}$ and Andrea Ballabio ${ }^{1,2,3,4}$ \\ ${ }^{1}$ Telethon Institute of Genetics and Medicine, 80131 Naples, Italy \\ ${ }^{2}$ Department of Molecular and Human Genetics, Baylor College of Medicine, Houston, Texas 77030 \\ ${ }^{3} J a n$ and Dan Duncan Neurological Research Institute, Texas Children's Hospital, Houston, Texas 77030 \\ ${ }^{4}$ Medical Genetics, Department of Translational Medicine, Federico II University, 80131 Naples, Italy \\ Correspondence: ballabio@tigem.it
}

Recent evidence indicates that the importance of the lysosome in cell metabolism and organism physiology goes far beyond the simple disposal of cellular garbage. This dynamic organelle is situated at the crossroad of the most important cellular pathways and is involved in sensing, signaling, and transcriptional mechanisms that respond to environmental cues, such as nutrients. Two main mediators of these lysosomal adaptation mechanisms are the mTORC1 kinase complex and the transcription factor EB (TFEB). These two factors are linked in a lysosome-to-nucleus signaling pathway that provides the lysosome with the ability to adapt to extracellular cues and control its own biogenesis. Modulation of lysosomal function by acting on TFEB has a profound impact on cellular clearance and energy metabolism and is a promising therapeutic target for a large variety of disease conditions.

$\mathrm{C}_{\mathrm{m}}$ ell metabolism and growth rely on a tight balance between anabolic and catabolic processes. The lysosome plays a crucial role in maintaining this balance by mediating cellular catabolic processes. First described by Christian de Duve, the lysosome is a cellular organelle made of a single-lipid bilayer membrane and an acidic lumen (de Duve 2005), which contains a complex machinery of hydrolases that are devoted to the catabolism of a vast range of substrates (Schroder et al. 2010). Lysosomes are involved in tight "relationships" with other cellular structures. Such relationships are mediated by the lysosomal membrane and represent the main mechanism by which substrates are transported to the lysosome for degradation. The majority of extracellular substrates are transported to the lysosome via the endocytic pathway, and in particular through the fusion of the lysosome with late endosomes (Conner and Schmid 2003), whereas intracellular substrates reach the lysosome via fusion of autophagosomes with lysosomes along the autophagic pathway (He and Klionsky 2009). Thus, the lysosome has a central role in cellular catabolism and in intracellular trafficking by being at the crossroad between endocytic and autophagic pathways.

Editors: Sandra L. Schmid, Alexander Sorkin, and Marino Zerial

Additional Perspectives on Endocytosis available at www.cshperspectives.org

Copyright (C) 2014 Cold Spring Harbor Laboratory Press; all rights reserved; doi: 10.1101/cshperspect.a016907

Cite this article as Cold Spring Harb Perspect Biol 2014;6:a016907 


\section{Settembre and A. Ballabio}

In addition to late endosomes and autophagosomes, lysosomes are also able to fuse with the plasma membrane (Chieregatti and Meldolesi 2005). This process has two main consequences: translocation of components of the lysosomal membrane to the plasma membrane and secretion of lysosomal content. Both of these aspects have important functional relevance. The translocation of lysosomal membrane to the plasma membrane has a crucial role in plasma membrane repair (Reddy et al. 2001). When the plasma membrane is damaged lysosomes rapidly migrate to the injury site and seal the damaged area by fusing with the plasma membrane. On the other hand, extracellular secretion of the lysosomal content, a process known as lysosomal exocytosis, mediates important physiological processes, such as bone resorption by osteoclast and cytotoxicity of killer T lymphocytes (Mostov and Werb 1997; Logan et al. 2003). The central role of the lysosome in endocytic and auto- phagic pathways and in lysosomal exocytosis has a convergent functional significance. All these processes mediate, in different ways, cellular clearance. Substrates delivered to lysosomes by both endocytosis and autophagy can either be degraded by lysosomal enzymes or secreted in the extracellular domain by lysosomal exocytosis (Fig. 1).

The complex series of events that occur along the endocytic pathway, which lead to the formation of a mature lysosome, have been extensively described in the literature. The specialized structure of the lysosome has evolved to be able to degrade a large variety of both extracellular and intracellular substrates. As discussed above, this is achieved by the combined action of membrane-associated and lumenal proteins. Lysosomal membrane proteins are involved in the trafficking of substances in and out of the lysosome and in maintaining proper ionic concentration and $\mathrm{pH}$ in the lumen (Schwake et al.

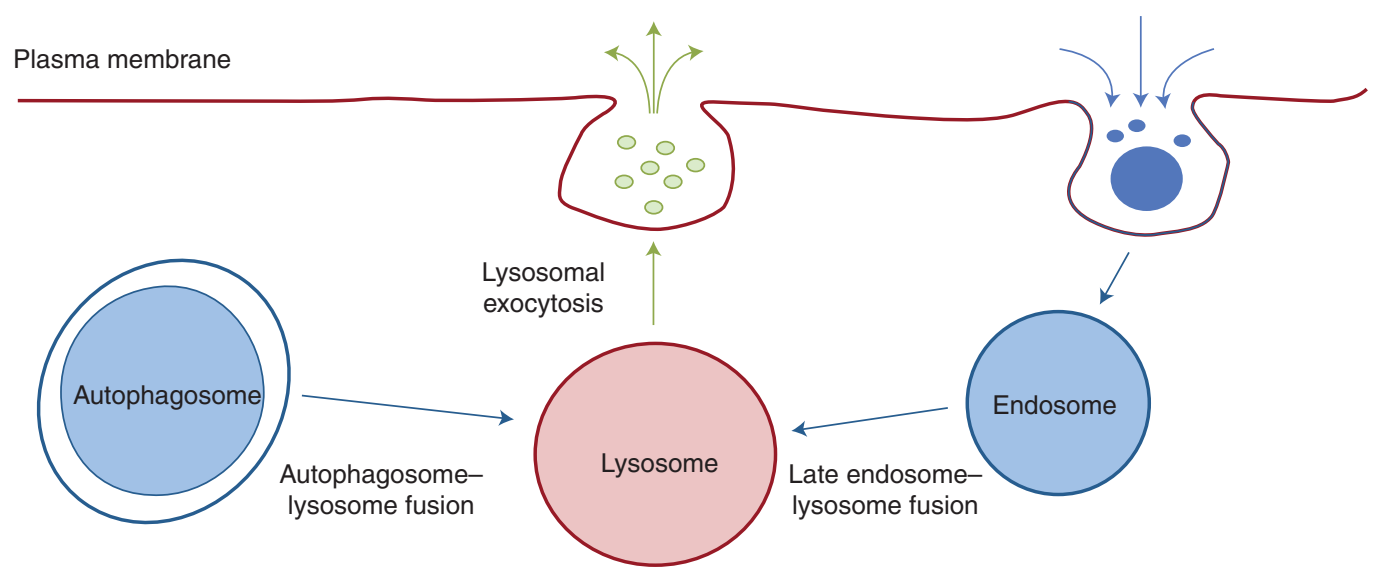

Cargo delivery

Degradation

Secretion

Figure 1. The lysosome and cellular clearance. The figure depicts the three major aspects of lysosome-mediated cellular clearance: cargo targeting to lysosomes, substrate degradation, and secretion. Lysosomes receive extracellular material via endocytosis and intracellular material via autophagy. In these processes, lysosomes fuse with late endosomes and with autophagosomes, respectively. Subsequently, substrates are degraded by lysosomal hydrolases and the resulting breakdown products are used to generate new cellular components and energy in response to the nutritional needs of the cell. Lysosomes also undergo $\mathrm{Ca}^{2+}$-regulated exocytosis to secrete their content into the extracellular space and to repair damaged plasma membranes. 
2013). They also mediate fusion of the lysosome with other cellular structures. Lipids associated to the lysosomal membrane, such as phosphoinositides, are involved in lysosomal reformation and lysosomal identity (Luzio et al. 2007; Rong et al. 2012). Deficiency of either PI(3)P or $\mathrm{PI}(3,5) \mathrm{P}_{2}$ phosphoinositides leads to lysosomal swelling and inhibition (Michell et al. 2006; Ho et al. 2012). Furthermore, defective phosphorylation of $\mathrm{PI}(4) \mathrm{P}$ to $\mathrm{PI}(4,5) \mathrm{P}_{2}$ was shown to be responsible for constitutive lysosomal tubulation and release of lysosomal cargo (Sridhar et al. 2013).

Lumenal hydrolases are the executors of lysosomal catabolic function. They include members of protein families such as sulfatases, glycosidases, peptidases, phosphatases, lipases, and nucleases (Sleat et al. 2013), which allow the lysosome to hydrolyze a vast repertoire of substrates, including sugars, proteins, lipids, and nucleic acids. Most lysosomal hydrolases reach the lysosome by a receptor-mediated process that recognizes mannose-6-phosphate residues (Saftig and Klumperman 2009).

Acidic $\mathrm{pH}$ and proper ionic concentration are fundamental conditions for lysosomal function as most lysosomal hydrolases have an acidic pH optimum (Mindell 2012). The vacuolar ATPase (V-ATPase) is a large multimeric channel that uses the energy derived from ATP hydrolysis to transport protons across the lysosomal membrane to generate the acidic $\mathrm{pH}$ of the lysosomal lumen (Mindell 2012). Remarkably, the most potent compounds that inhibit lysosomal function act on the lysosomal acidification machinery and mutations affecting lysosomal acidification cause lysosomal disorders (Ballabio and Gieselmann 2009). Lysosomal calcium levels are also extremely important for lysosomal function. They are regulated by the transient receptor potential (TRP) family member mucolipin 1 (MCOLN1), whose mutations cause Mucolipidosis IV (Bargal et al. 2000; Bassi et al. 2000; Shen et al. 2012).

Degradation of substrates by lysosomes has two major consequences: (1) the degradation and recycling of complex molecules (e.g., glycosaminoglycans, complex lipids, or proteins) to generate fundamental units (e.g., glucose, free fatty acids, and amino acids) that will be used for biosynthetic pathways and energy production (Singh et al. 2009; Rabinowitz and White 2010), and (2) the removal of exhausted organelles (e.g., mitochondria) whose intracellular accumulation could be detrimental to the cell (Settembre et al. 2008; Lieberman et al. 2012). The export of substances from the lysosome back into the cytosol is achieved through poorly defined mechanisms that involve the use of specific export channels or through a selective efflux during membrane remodeling (Sagne and Gasnier 2008; Liu et al. 2012).

The crucial role played by the lysosome in several physiological processes has been further characterized by the identification of lysosomal dysfunction as a major determinant of the pathogenesis of a variety of disease conditions. Lysosomal storage disorders (LSDs) are a group of $\sim 60$ different disease conditions attributable to mutations in genes encoding proteins that play an important role in lysosomal function (Cox and Cachon-Gonzalez 2012). These include lysosomal lumenal and membrane proteins and nonlysosomal proteins that participate in lysosomal function. In all cases the consequence of lysosomal dysfunction is the progressive accumulation of undegraded substrates leading to impairment of several aspects of cellular function, such as trafficking, signaling, and cell death (Ballabio and Gieselmann 2009; Lieberman et al. 2012). At the organism level this is associated with a multisystemic and progressive phenotype characterized by the involvement of multiple organs and tissues. A very common feature of LSDs is early-onset neurodegeneration with severe and often fatal consequences (Jeyakumar et al. 2005).

Recent studies indicate that lysosomal dysfunction is also a major determinant of common neurodegenerative diseases, such as Parkinson's, Alzheimer's, and Huntington's disease (Metcalf et al. 2010; Shachar et al. 2011; Settembre et al. 2013b). Aggregate-prone proteins, such as expanded huntingtin (HTT) in Huntington's disease and mutated $\alpha$-synuclein in Parkinson's disease, impair the lysosomal-autophagic pathway by inhibiting cargo recognition by autophagosomes (Martinez-Vicente et al. 2010; Win- 
slow et al. 2010). Protein aggregates may be cleared by boosting the lysosomal-autophagic pathway (Harris and Rubinsztein 2012; Rubinsztein et al. 2012). Of particular interest is the finding of mutations in the gene encoding the lysosomal enzyme $\beta$-glucocerebrosidase in a significant number of patients with Parkinson's disease, particularly among Ashkenazi Jews (Aharon-Peretz et al. 2004; Shachar et al. 2011). It has been proposed that $\beta$-glucocerebrosidase deficiency leads to an increased accumulation of glucosylceramide in the lysosome, with consequent increase and stabilization of soluble $\alpha$-synuclein oligomers and of amyloid fibrils. Accumulation of $\alpha$-synuclein impairs the trafficking of newly synthesized $\beta$-glucocerebrosidase to the lysosome leading to further glucosylceramide accumulation (Mazzulli et al. 2011). Additional mutations in genes involved in the endolysosomal pathway have been identified in patients with late-onset neurodegenerative diseases (Verhoeven et al. 2003; Skibinski et al. 2005; Ramirez et al. 2006; Sun et al. 2008; Lee et al. 2010; Shachar et al. 2011; Zimprich et al. 2011; Coen et al. 2012).

Finally, lysosomal dysfunction is a major contributor to the pathogenesis of a plethora of disease conditions including disorders of lipid and glucose metabolism, infectious diseases, bone diseases, and disorders of the immune system (Settembre et al. 2013b). Even the process of aging appears to be associated with a progressive decline of lysosomal function ( $\mathrm{Ru}-$ binsztein et al. 2011). Thus, although it is well established that genetic mutations in lysosomal enzymes lead to development of LSDs, it is becoming evident that more subtle changes in lysosomal function may be important contributors to the development of many disease processes.

\section{THE CONCEPT OF LYSOSOMAL ADAPTATION}

The ability to interact with the surrounding environment and respond to environmental changes is one of the most important features of all living organisms and a major force driving evolution. A prominent example of adaptation is how an organism copes with changes in nutrient availability. During nutrient deprivation (i.e., starvation) the whole organism generates a response that leads to inhibition of anabolic pathways, a condition in which energy is used for biosynthesis of macromolecules, and activation of catabolism, generating energy from breakdown of complex molecules. Cells have developed sophisticated mechanisms to adapt to different levels and nature of nutrients both in vivo, in different organs and tissues, and in cell culture.

Until recently, the lysosome has been considered a static organelle, with little or no influence from external environments. Indeed, variations in the intracellular catabolic activity were mostly attributed to changes in the rates of either the endocytic or autophagic pathways. These processes involve cargo targeting to lysosomes, rather than the function of the lysosome itself. However, this view of the lysosome has progressively changed into a much broader and dynamic perspective (Settembre et al. 2013a). The ability of the lysosome to adapt to different environmental cues became evident with the discovery that lysosomal function is regulated at both transcriptional and posttranscriptional levels (Sardiello et al. 2009; Settembre et al. 2011) and is able to respond to both extracellular and intracellular cues (Settembre et al. 2011). This novel concept of "lysosomal adaptation" is important for our understanding of basic biological processes, ranging from cellular clearance to the control of cellular energy metabolism.

\section{TRANSCRIPTIONAL CONTROL OF LYSOSOMAL BIOGENESIS AND FUNCTION}

Highly specialized cellular functions can be coordinated through the genetic control of organelle biogenesis. The catabolic requirements of the cell vary depending on tissue type, age, and environmental conditions; therefore it is reasonable to expect the presence of systems that allow regulation of lysosomal function. Another emerging aspect of lysosome biology is to understand how lysosomal turnover is regulated. It was shown that in certain situations such 
as bacterial infections or chemical damage, galectin 8 targets damaged lysosomes for autophagy degradation (Thurston et al. 2012). Further studies are required to fully understand how lysosomal turnover is regulated.

A systems biology approach was used to identify the transcriptional network that regulates lysosomal function (Fig. 2). Integrated analysis of publicly available microarray data revealed that several genes encoding lysosomal proteins are coexpressed in various tissues and cell types, as well as under different conditions (Sardiello et al. 2009). Promoter analysis of lysosomal genes revealed that many of them contain a palindromic 10-base site that was previously identified as a specific version of a known target site for basic helix-loop-helix (bHLH) transcription factors, also known as an E-box
(Hemesath et al. 1994). Together these data led to the identification of the coordinated lysosomal enhancement and regulation (CLEAR) gene network, which controls lysosomal biogenesis and function (Sardiello et al. 2009). The CLEAR network was found to include genes that encode proteins involved in several aspects of endolysosomal biogenesis. In addition, genes involved in lysosome-related functions, such as autophagy, exocytosis, endocytosis, phagocytosis, the immune response, and lipid catabolism were also identified as members of the CLEAR network (Palmieri et al. 2011).

All four bHLH transcription factors that belong to the MiT subfamily (MITF, transcription factor EB [TFEB], TFE3, and TFEC) have the ability to bind CLEAR sites in the promoters of target genes (Hemesath et al. 1994). In addition,

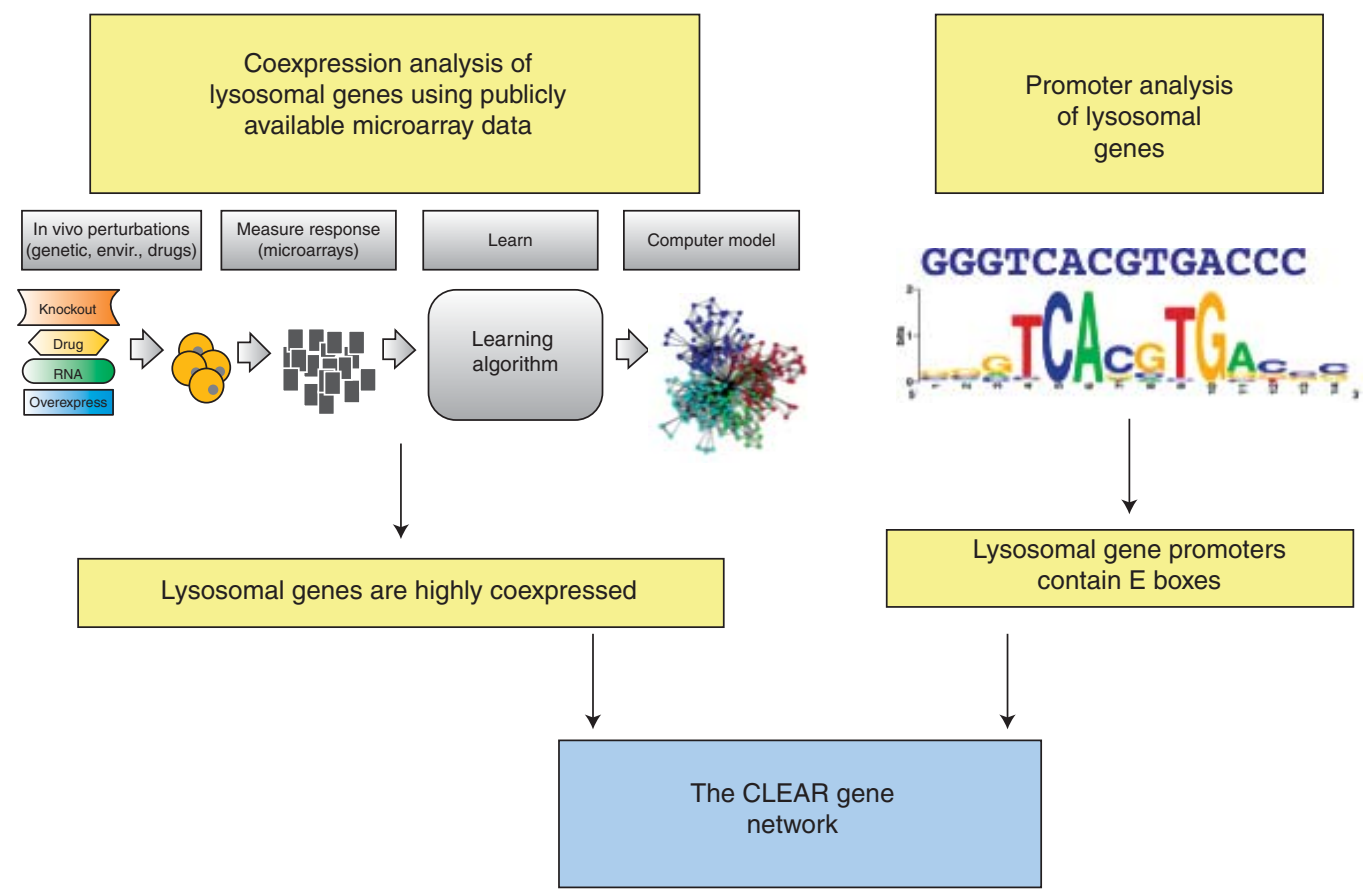

Figure 2. Identification of the CLEAR gene network. A systems biology approach was used to test the hypothesis that lysosomal genes are coregulated. The analysis of the expression behavior of genes encoding lysosomal proteins was analyzed using publicly available microarray data and revealed that they are coexpressed. Pattern discovery analysis revealed the presence of a palindromic 10-base site in the promoters of known lysosomal genes. This sequence was previously identified as a specific version of a known target site for basic helix-loophelix (bHLH) transcription factors, also known as an E-box. Thus, these two independent approaches-namely, coexpression and promoter analyses-identified a new gene network that was named CLEAR (coordinated lysosomal expression and regulation). envir., environment. 
they physically interact with each other and can bind DNA as both homodimers and heterodimers (Hemesath et al. 1994). This promiscuity suggests that functional specificity may be owing to differences of tissue/context-specific regulation. MITF is expressed during embryonic development and regulates the differentiation of melanocytes and retinal pigment epithelium (Levy et al. 2006). It is responsible for pigment cell-specific transcription of the melanogenesis enzyme genes by regulating the expression of tyrosinase (TYR) and tyrosinase-related protein 1 (TYRP1). It also plays a critical role in the differentiation of various cell types, such as neural crest-derived melanocytes, mast cells, osteoclasts, and optic cup-derived retinal pigment epithelium (Price and Fisher 2001; Hershey and Fisher 2004; Steingrimsson et al. 2004). MITF is mutated in patients with the pigmentary and deafness disorder Waanderburg Syndrome Type 2A (Watanabe et al. 1998). The other members of the MiT family (i.e., TFEB, TFE3, and TFEC) have a more ubiquitous expression and function. However, although TFEB homozygous null mice show embryonic lethality owing to a placental vascularization defect (Steingrimsson et al. 1998), both TFE3 and TFEC knockout mice have no apparent phenotypes (Steingrimsson et al. 2002). In addition, the combined loss of both MITF and TFE3 genes in mice results in a defect of osteoclast development and function (Steingrimsson et al. 2002). Both TFEB and TFE3 are involved in chromosomal translocations associated with renal cell carcinomas (Kuroda et al. 2012). However, the mechanism underlying these tumors has not been identified yet. Together these observations suggest that there is a considerable promiscuity and redundancy among MiT transcription factors. The functional significance of such redundancy awaits further investigation.

Subsequent experiments showed that the transcription factor EB (TFEB) positively regulates the expression of lysosomal genes and acts as a master regulator of lysosomal biogenesis (Sardiello et al. 2009). Both gain and loss-offunction experiments have shown that TFEB regulates several aspects of lysosomal function. TFEB overexpression increases the number of lysosomes and the levels of lysosomal enzymes and enhances lysosomal catabolic activity (Sardiello et al. 2009). Further studies showed that TFEB also regulates the autophagic pathway by positively regulating autophagy genes, inducing autophagosome formation and autophagosome-lysosome fusion and enhancing the degradation of autophagy substrates (Settembre et al. 2011). Furthermore, TFEB was found to induce lysosomal exocytosis (Medina et al. 2011). Overexpression of TFEB in a variety of cell types resulted in the translocation of lysosomal membrane markers, such as LAMP1, to the plasma membrane, a typical sign of lysosomal exocytosis, and in the active secretion of the lysosomal content in the culture medium (Medina et al. 2011). This function of TFEB is highly dependent on cellular calcium levels and is mediated by the lysosomal calcium channel mucolipin 1 (Medina et al. 2011).

\section{LYSOSOMAL NUTRIENT SENSING: THE LYSOSOME AS A SIGNALING HUB}

The first example of a specific process by which the lysosome receives information from the extracellular environment and generates a signaling response is nutrient-mediated activation of the mechanistic target of rapamycin complex 1 (mTORC1) kinase complex on the lysosomal surface (Zoncu et al. 2011; Bar-Peled and Sabatini 2012). This mechanism is mediated by a complex machinery, herein referred to as lysosomal nutrient sensing (LYNUS) (Fig. 3) (Settembre et al. 2013b). This machinery involves several protein complexes located on the lysosomal surface, most of them interacting with each other, whose main function is to regulate cell growth and metabolism through the mTORC1 signaling pathway. The localization of such vital cellular machinery on the lysosome reveals a completely novel role for this organelle as a signaling hub. The mTORC1 complex includes the regulatory proteins RAPTOR (regulatory-associated protein of mTOR), mLST8 (mammalian lethal with SEC13 protein), and DEPTOR (DEP domain-containing mTOR-interacting protein) (Efeyan et al. 2012). This complex physically interacts with Rag GTPases 
Lysosomal Adaptation

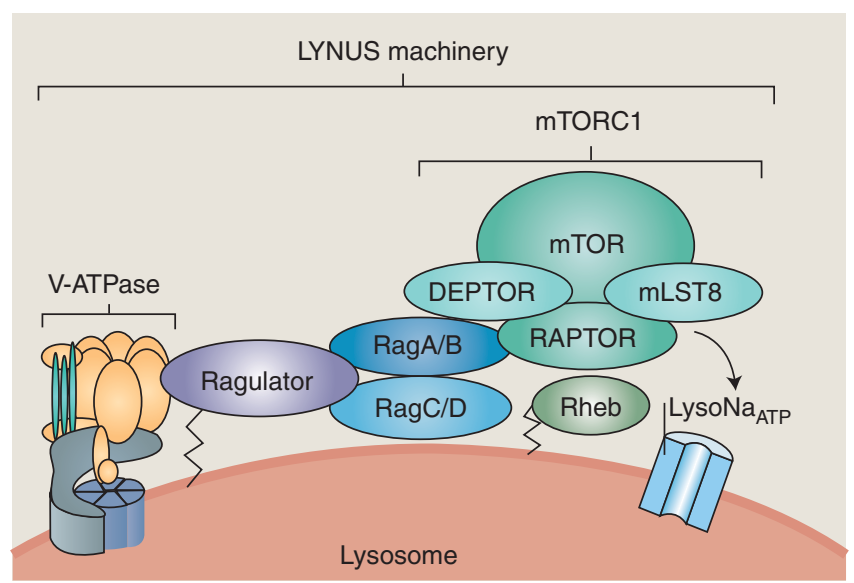

Figure 3. The LYNUS machinery. A complex machinery, made of several interacting protein complexes was identified on the lysosomal surface. This machinery, herein named lysosomal nutrient sensing (LYNUS), includes regulatory proteins associated with mTOR, such as RAPTOR (regulatory-associated protein of mTOR), mLST8 (mammalian lethal with SEC13 protein), and DEPTOR (DEP domain-containing mTORinteracting protein), and Rag GTPases (RagA or RagB and RagC or RagD), which activate mTORC1 on the lysosomal surface. A complex known as Ragulator mediates the activation and docking of Rag GTPases to the lysosomal membrane. The small GTPase Ras homolog enriched in brain (Rheb) is also involved in the growth factor-mediated activation of mTORC1. The V-ATPase complex functions in amino acid sensing and mediates amino acid-sensitive interactions between Rag GTPases and Ragulator, which is the initial step in lysosomal signaling. The endolysosomal ATP-sensitive $\mathrm{Na}^{+}$-permeable channel (lysoNaATP), which comprises the subunits two pore calcium channel 1 (TPC1) and TPC2, is located on the lysosomal membrane, and it has recently been shown to interact with mTORC1 and to participate in nutrient sensing. (Figure is based on data from Settembre et al. 2013b.)

(RagA or RagB and RagC or RagD) and with the small GTPase RAS homolog enriched in brain (Rheb) (Inoki et al. 2003; Tee et al. 2003), which activate mTORC1 on the lysosomal surface (Sancak et al. 2008). A complex known as Ragulator mediates the activation and docking of Rag GTPases to the lysosomal membrane (Sancak et al. 2010). Mechanistically, amino acidactivated Ragulator has guanine exchange factor (GEF) activity on RagA and B resulting in their induction (Bar-Peled et al. 2012). The activation of Ragulator depends on the level of lysosomal luminal amino acids. This information is conveyed through a poorly defined inside-out mechanism that involves the vacuolar $\mathrm{H}^{+}$-adenoside triphosphate ATPase (V-ATPase) complex which senses the level of lysosomal luminal amino acids and mediates the amino acid-sensitive activation of Ragulator (Zoncu et al. 2011). Thus, the V-ATPase and the Ragulator complex convey a lysosomal signal (i.e., the ami- no acid content) that results in mTORC1 activation. Selective depletion of amino acids from the lysosome, as well as the inhibition of lysosomal function, causes the release of mTORC1 from the lysosome and inactivation of its catalytic activity (Zoncu et al. 2011). The endolysosomal ATP-sensitive $\mathrm{Na}^{+}$-permeable channel (lysoNaATP) is also located on the lysosomal membrane, and it has recently been shown to interact with mTORC1 and to participate in nutrient sensing (Cang et al. 2013). A similar, albeit less well characterized, mechanism mediates mTORC1 activation by glucose (Efeyan et al. 2013). This mechanism may involve Spinster, a putative lysosomal sugar transporter, which controls mTORC1 activity (Rong et al. 2011). These observations uncovered an unpredicted role of the lysosome as a sensing center that regulates $\mathrm{mTORC} 1$ activity.

The downstream effects of mTORC1 activation are activation of cell growth and of protein 
and lipid biosynthesis (Laplante and Sabatini 2012). Conversely, inhibition of mTORC1 results in down-regulation of biosynthetic pathways and activation of cell catabolism, mainly through the induction of the lysosomal-autophagic pathway (Laplante and Sabatini 2012). The physiological role of this regulatory mechanism was studied in vivo using genetically engineered mice. In mice that carry a constitutively active RagA the activity of mTORC1 was increased, even in fasting conditions. These mice develop normally but die shortly after birth owing to failure of the physiological activation of autophagy that occurs between birth and the first meal owing to a drop of glucose levels (Efeyan et al. 2013). The activation of autophagy in this period is required to generate free amino acids to sustain de novo glucose production through the gluconeogenic pathway (Kuma et al. 2004).

Subsequent studies showed a tight link between the signaling mechanism mediated by the mTORC1 kinase complex on the lysosomal surface and the above-described transcriptional regulation of lysosomal function mediated by TFEB. This link has an essential importance in the lysosomal adaptation to nutrient availability and in the regulation of cellular energy metabolism.

\section{A LYSOSOME-TO-NUCLEUS SIGNALING MECHANISM}

In normal standard conditions TFEB is located in the cytoplasm, whereas during starvation or lysosomal dysfunction, TFEB rapidly translocates to the nucleus where it binds the CLEAR sites in the promoters of target genes (Sardiello et al. 2009; Settembre et al. 2011). Phosphorylated TFEB is located predominantly in the cytoplasm, whereas the dephosphorylated form is in the nucleus (Settembre et al. 2011; Martina et al. 2012; Roczniak-Ferguson et al. 2012; Settembre et al. 2012). At least ten different phosphorylation sites are present in the TFEB protein. Among them, serine 142 and 211 play a crucial role in determining the subcellular localization of TFEB. The observation that TFEB subcellular localization is controlled by its phos- phorylation status suggested the presence of a link between the mTORC1-mediated signaling mechanism on the lysosomal surface and TFEB function. Indeed mTORC1, as well as ERK2 (Settembre et al. 2011) was found to phosphorylate TFEB (Pena-Llopis et al. 2011; Settembre et al. 2011; Martina et al. 2012; Roczniak-Ferguson et al. 2012; Settembre et al. 2012). Studies performed in osteoclasts showed that protein kinase $C \beta$ also phosphorylates TFEB, but in a different region, resulting in the stabilization of the protein (Ferron et al. 2013).

Interestingly, within the cytoplasm TFEB can be detected both in the cytosol and on the lysosomal surface (Settembre et al. 2011, 2012; Martina et al. 2012; Roczniak-Ferguson et al. 2012). Several members of the 14-3-3 protein family play an important role in the cytoplasmic retention of phosphorylated TFEB (Martina et al. 2012; Roczniak-Ferguson et al. 2012). It has been suggested that the interaction between phosphorylated TFEB and 14-3-3 proteins masks a TFEB nuclear localization signal, thus preventing its nuclear translocation (Roczniak-Ferguson et al. 2012).

The TFEB nuclear translocation mechanism provides cells with the ability to modulate lysosomal biogenesis to respond to environmental cues (Settembre et al. 2011, 2012; Martina et al. 2012; Roczniak-Ferguson et al. 2012). Nutrients and growth factors influence TFEB subcellular localization and function by regulating the activities of mTORC1 and ERK2 kinases. Inhibition of mTORC1 and ERK2 activities during starvation promotes TFEB nuclear translocation and activation of the CLEAR gene network. Interestingly, nutrients regulate TFEB activity also at the transcriptional level by a nutrientsensitive autoregulatory loop. Once in the nucleus TFEB is able to bind to its own promoter in a starvation-dependent manner and to induce its own expression. Thus, the regulation of TFEB activity by nutrients involves a dual mechanism: a rapid, phosphorylation-dependent posttranscriptional switch, which is responsible for the nuclear translocation of TFEB, and a transcriptional autoregulatory component, which allows for a slower more sustained response (Fig. 4) (Settembre et al. 2013a). 


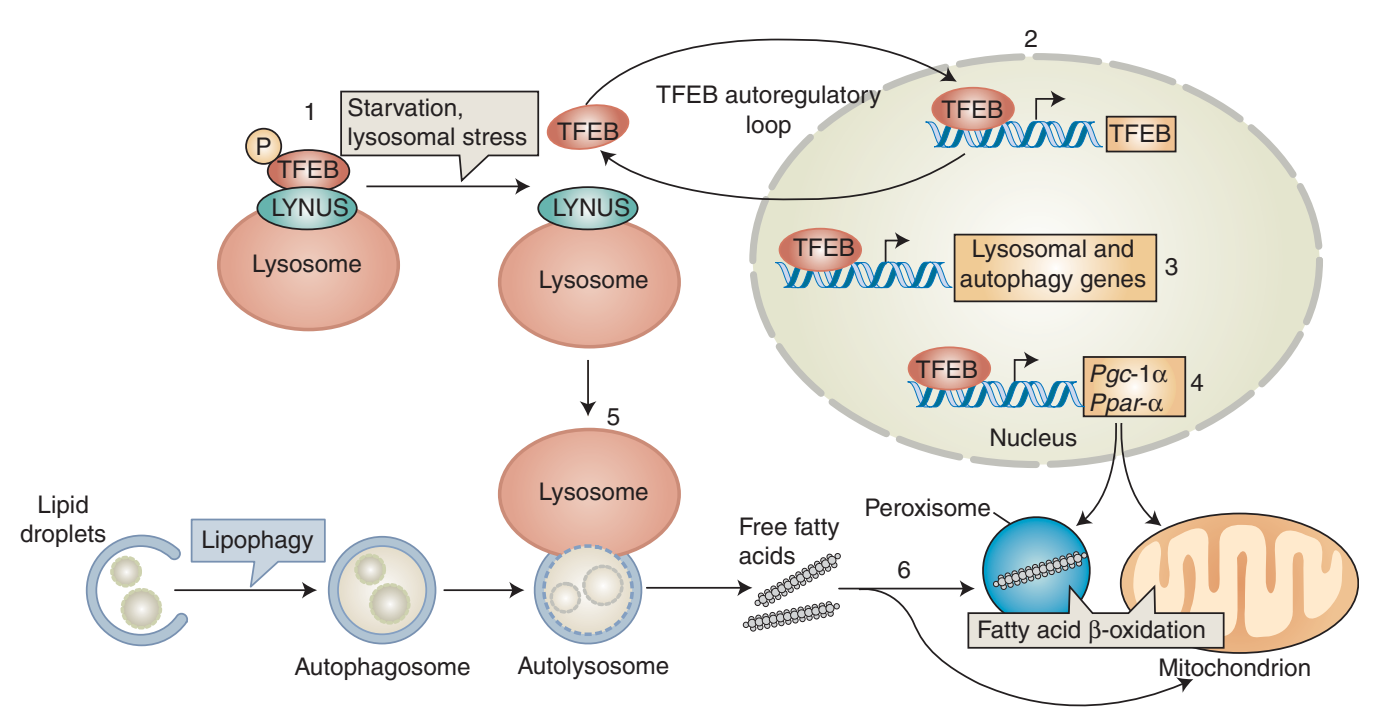

Figure 4. Model of TFEB regulation and function during starvation. This model illustrates how TFEB mediates the starvation response by regulating lipid catabolism. In the presence of sufficient nutrients, TFEB interacts with the LYNUS machinery, which senses lysosomal nutrient levels via the vacuolar ATPase (V-ATPase) complex, and is phosphorylated by mammalian target of rapamycin complex 1 (mTORC1) on the lysosomal surface (1). This keeps TFEB inactive by cytosolic sequestration. During starvation, mTORC1 is released from the LYNUS machinery and becomes inactive. Thus, TFEB can no longer be phosphorylated by mTORC1 and translocates to the nucleus, where it induces its own transcription (2). Therefore, starvation regulates TFEB activity through a dual mechanism that involves a posttranslational modification (that is, phosphorylation) and a transcriptional autoregulatory loop. Once in the nucleus, TFEB regulates the expression of genes involved in the lysosomal-autophagy pathway (3), as well as of Ppar- $\alpha$ (peroxisome proliferator-activated receptor- $\alpha$ ) and Pgc-1 $\alpha$ (PPAR- $\gamma$ coactivator $1 \alpha$ ) and their target genes (4). In this way, TFEB controls the starvation response by activating both lipophagy (5) and fatty acid $\beta$-oxidation (6). (Figure is based on data from Settembre et al. 2013a,b.)

Together these observations indicate that the lysosome controls its own biogenesis and function. As shown in Fig. 3, in fully fed cells, TFEB interacts with the LYNUS machinery, and in particular with the Rag proteins on the lysosomal surface and is phosphorylated by mTORC1 (Martina and Puertollano 2013). This phosphorylation keeps TFEB inactive by preventing its nuclear translocation. During starvation, the decrease in lysosomal amino acid levels inhibits mTORC1 activity and induces the nuclear translocation of unphosphorylated TFEB. Once in the nucleus, TFEB activates a transcriptional network that enhances autophagy and lysosomal catabolism (Settembre et al. 2012). Thus, the lysosome senses its nutrient status via the LYNUS machinery, which transforms nutrientsensing information into a signaling mechanism via mTORC1. The signal is subsequently conveyed to the nucleus by TFEB to elicit a transcriptional response (Settembre et al. 2012). Another important function of this regulatory mechanism may be to exert a quality control system to replenish lysosome numbers in critical conditions. In fact, inhibition of lysosomal function promotes nuclear translocation of TFEB as an attempt to induce biogenesis of new lysosomes and autophagosomes (Settembre et al. 2012).

\section{THE LYSOSOME REGULATES CELLULAR ENERGY METABOLISM VIA TFEB}

For a long time it has been thought that lipid catabolism (i.e., lipolysis) was performed mainly by cytosolic neutral lipases. However, the im- 
portance of the lysosome in lipid catabolism became evident when deficiency of the lysosomal acid lipase was observed in a severe type of LSD, Wolman's disease, which is associated with significant intracellular fat accumulation (Du et al. 1998). Lysosomal dysfunction was also shown to cause an altered energy balance in mouse models of different types of LSDs (Woloszynek et al. 2007).

Several studies have shown the importance of autophagy in lipid catabolism. Lipid droplets are shuttled by autophagosomes to lysosomes, where they are hydrolyzed into free fatty acids (FFAs) and glycerol. This process has been named macrolipophagy (Singh et al. 2009; Singh and Cuervo 2011). Remarkably, excessive lipid overload inhibits autophagy (Yang et al. 2010; Rodriguez-Navarro and Cuervo 2012; Rodriguez-Navarro et al. 2012), whereas restoring liver autophagy ameliorates the metabolic phenotype of genetically induced obese mice (Ob/Ob) (Yang et al. 2010). Similar observations were made in Caenorhabditis elegans, in which lysosomal lipases LIPL-1 and LIPL-3 were identified as key enzymes breaking down lipid-droplet fats through macrolipophagy (O’Rourke and Ruvkun 2013).

These studies suggested that regulation of the lysosomal-autophagic pathways might have an effect on lipid catabolism and on cellular energy metabolism. Indeed, gain and lossof-function experiments of TFEB in the mouse liver showed its crucial role in the regulation of lipid metabolism (Settembre et al. 2013a). Viral-mediated TFEB overexpression in the mouse liver, followed by transcriptome analysis, revealed up-regulation of genes involved in several steps of lipid breakdown, such as lipophagy, fatty acid oxidation, and ketogenesis. Furthermore, the transcriptional response elicited by starvation in the liver was significantly blunted in liver-specific TFEB conditional knockout mice (Settembre et al. 2013a). Among the genes regulated by TFEB in the liver of high relevance are Ppar- $\alpha$ (peroxisome proliferatoractivated receptor- $\alpha$ ) and Pgc-1 $\alpha$ (PPAR- $\gamma$ coactivator $1 \alpha$ ), which are key regulators of lipid metabolism in response to starvation (Finck and Kelly 2006; Settembre et al. 2013a). In par- ticular, TFEB was shown to directly bind to the $P g c-1 \alpha$ promoter in a starvation-sensitive manner (Settembre et al. 2013a).

Liver-specific TFEB overexpression and knockout studies were performed in diet-induced obese mice to study the consequences of the transcriptional effect of TFEB on genes involved in lipid metabolism. Remarkably, TFEB overexpression enhanced liver fat catabolism, prevented diet-induced obesity, and rescued the metabolic syndrome, whereas TFEB loss of function enhanced the obese phenotype (Settembre et al. 2013a). The effects of TFEB on lipid metabolism were found to be dependent on a functional autophagic pathway and were suppressed in Atg7 KO mice in which autophagy is blocked, indicating that TFEB induces lipid catabolism both by promoting lipophagy and by inducing fatty acid oxidation via $P g c-1 \alpha$ (Fig. 4) (Settembre et al. 2013a).

Similarly to human TFEB, the C. elegans orthologous gene $h l h-30$ was also found to respond to starvation and to control genes involved in lipid catabolism (O'Rourke and Ruvkun 2013; Settembre et al. 2013a). Thus, the lysosome controls the cellular response to nutrient levels and induces, via TFEB, a metabolic switch that allows the organism to generate energy from stored lipids. These observations shed new light on the role of the lysosome in cellular energy metabolism and suggest a possible mechanism underlying obesity and metabolic syndrome. A proposed model for the regulation of TFEB by nutrients and the role of TFEB in lipid catabolism is illustrated in Fig. 4.

\section{TFEB AS A TOOL TO PROMOTE CELLULAR CLEARANCE IN HUMAN DISEASE}

TFEB function impacts all aspects of cellular clearance. It regulates the cargo delivery of substrates by inducing autophagosome biogenesis and autophagosome-lysosome fusion, promotes substrate degradation by raising the levels of lysosomal enzymes, and favors the release of storage material outside the cells by inducing lysosomal exocytosis. The impact of TFEB on cellular clearance identifies this pathway as a new therapeutic target for a variety of diseases. 
Lysosomal Adaptation

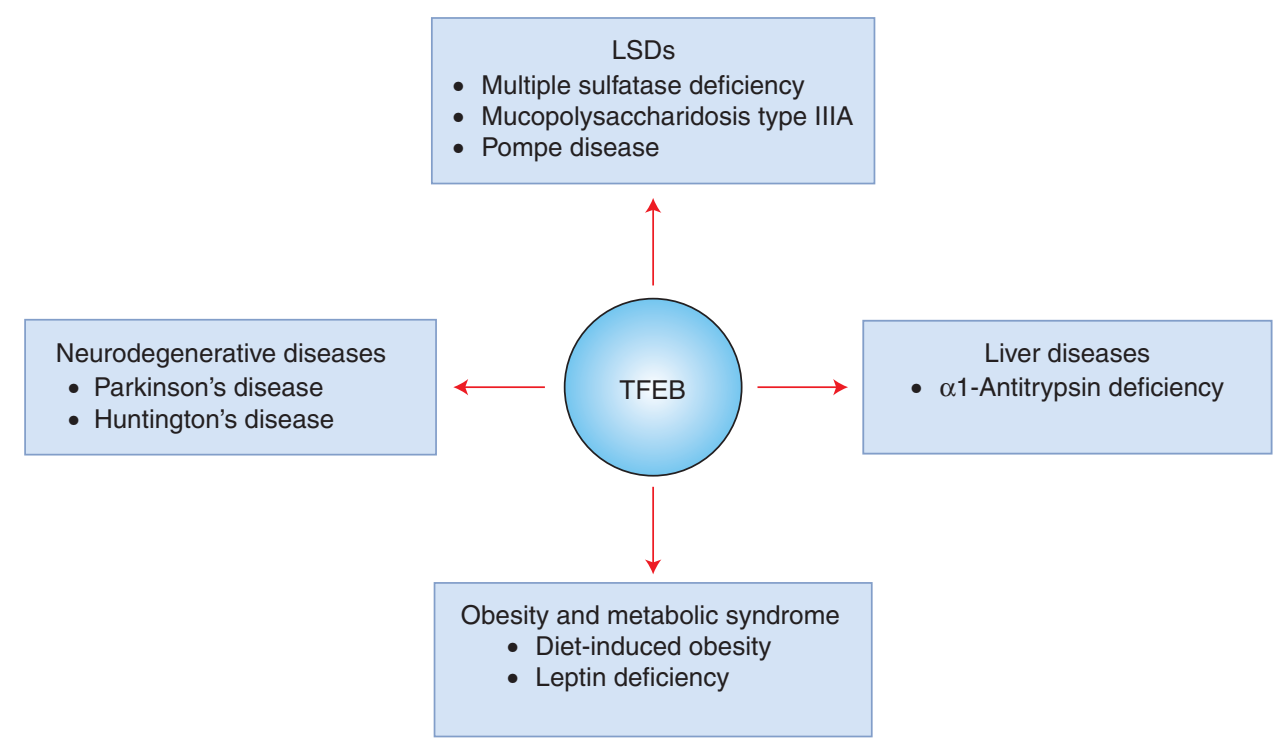

Figure 5. TFEB as a tool to promote cellular clearance in human disease. Human diseases for which viralmediated TFEB-overexpression-induced cellular clearance and ameliorated disease phenotype in mouse models.

Indeed TFEB overexpression promoted cellular clearance and rescued the disease phenotype in several diseases (Fig. 5). Viral-mediated gene transfer, using adeno-associated viruses (AAVs), was elected as a strategy to deliver TFEB in vivo to the affected tissues of mouse models of LSDs. AAV-mediated TFEB overexpression in mouse models of multiple sulfatase deficiency (MSD) and mucopolysaccharidosis type IIIA (MPSIIIA), two severe types of LSDs characterized by accumulation of glycosaminoglycans (GAGs) (Settembre et al. 2007; Sorrentino et al. 2013), resulted in a significant reduction of GAG storage and of lysosomal size in a variety of tissues (Medina et al. 2011). Notably, this was associated with a reduction of inflammation and apoptosis, two common features of LSDs (Medina et al. 2011). Similar results were obtained in a completely different type of LSD, glycogenosis type II (Pompe disease), which is characterized by the accumulation of glycogen mostly in muscle, heart, and liver leading to progressive muscular and heart dysfunction (Spampanato et al. 2013). Intramuscular TFEB overexpression in a mouse model of Pompe disease significantly reduced glycogen accumulation and lysosomal vacuolization and improved autophagosome degradation. Interestingly, the clearance effect of TFEB was found to require a functional autophagic pathway, suggesting that autophagy plays an important role in glycogen degradation. Furthermore, TFEB-induced exocytosis of autophagolysosomes via their fusion with the plasma membrane (Spampanato et al. 2013).

Accumulating evidence indicates that common neurodegenerative diseases such as Parkinson's, Alzheimer's, and Huntington's, are associated with lysosomal and autophagy dysfunction (Wong and Cuervo 2010; Harris and Rubinsztein 2012). Induction of TFEB in a mouse model of Parkinson's disease, which was generated by chemical intoxication restored autophagosome clearance and attenuated death of dopaminergic neurons (Dehay et al. 2010). Similar results were obtained in another model of Parkinson's disease owing to $\alpha$-synuclein overexpression in which AAV-mediated delivery of TFEB to the brain rescued lysosomal dysfunction, promoted clearance of $\alpha$-synuclein oligomers, and resulted in significant neuroprotection (Decressac et al. 2013). Interestingly, microRNA-mediated inhibition of TFEB in this mouse model aggravated the disease phe- 
notype in dopamine neurons (Decressac et al. 2013).

Furthermore, TFEB was found to mediate the ability of PGC- $1 \alpha$ to promote cellular clearance and decrease neurotoxicity in a mouse model of Huntington's disease (Tsunemi et al. 2012), whereas TFEB overexpression in the liver of a mouse model of $\alpha 1$-antitrypsin deficiency resulted in the clearance of mutated protein aggregates and rescue of liver fibrosis phenotype (Pastore et al. 2013). Finally, of particular interest is the recent finding that ce-TFEB or hlh-30 or HLH-30 promotes longevity in C. elegans (Lapierre et al. 2013) suggesting that modulation of lysosomal function may even prevent aging and prolong lifespan.

These results indicate that the ability of TFEB to promote cellular clearance may have very broad applications in very different disease conditions (Fig. 5). The mechanism by which TFEB promotes cellular clearance is likely to be the result of its combined effects on lysosomal biogenesis, autophagy, and lysosomal exocytosis.

\section{CONCLUDING REMARKS AND FUTURE PERSPECTIVES}

The "dangerous liaison" between the mTORC1 kinase complex and the TFEB transcription factor on the lysosomal surface has revealed a completely novel role for the lysosome. The mTORC1-TFEB axis is the first example of a lysosome-to-nucleus signaling mechanism, which provides the lysosome with the ability to adapt to environmental cues by sensing its nutrient content and generating a transcriptional response. This mechanism controls cellular clearance and energy metabolism and has significant implications in health and disease.

These newly discovered dynamic features, which once and for all disprove the old view of the lysosome as a static organelle, stimulate further investigations. It will be particularly important to determine how lysosome number, size, content, and function vary in different cell types and tissues, among different individuals and in response to different physiological and pathological conditions. To achieve this, classical cell biology approaches should be com- bined with in vivo studies in transgenic mice under different environmental conditions and/ or genetic manipulations.

The study of the role of the lysosome in human diseases also requires broader approaches. The analysis of patient-derived tissues by using omics-type approaches, such as transcriptomics, proteomics, and lipidomics, may reveal new roles, both positive and negative, of the lysosomal system in human diseases. Furthermore, variations in the DNA sequence of genes encoding lysosomal proteins may be identified in the population by whole genome and exome sequencing. These DNA variants may affect lysosomal function and have either a predisposing or protective effects on disease development.

Hopefully, the body of knowledge on lysosomal structure, function, regulation, and variation, which will be generated by these studies, will provide us with the ability to modulate lysosomal function in a specific and targeted way and according to our needs. This may represent a revolutionary approach for the therapy of a broad variety of devastating human diseases.

\section{ACKNOWLEDGMENTS}

We thank G. Diez-Roux for a critical reading of the manuscript, helpful discussions, and support in manuscript preparation. We acknowledge the support of the Italian Telethon Foundation grant TGM11CB6 (C.S. and A.B.), the Dulbecco Telethon Institute grant S12008TELB (C.S), the Beyond Batten Disease Foundation (C.S. and A.B.), European Research Council Advanced Investigator grant 250154 (A.B.), March of Dimes \#6-FY11-306 (A.B.), and a U.S. National Institutes of Health grant R01 NS078072-01A1.

\section{REFERENCES}

Aharon-Peretz J, Rosenbaum H, Gershoni-Baruch R. 2004. Mutations in the glucocerebrosidase gene and Parkinson's disease in Ashkenazi Jews. $N$ Engl J Med 351: $1972-1977$.

Ballabio A, Gieselmann V. 2009. Lysosomal disorders: From storage to cellular damage. Biochim Biophys Acta 1793: 684-696. 
Bar-Peled L, Sabatini DM. 2012. SnapShot: mTORC1 signaling at the lysosomal surface. Cell 151: 1390-1390 e1391.

Bargal R, Avidan N, Ben-Asher E, Olender Z, Zeigler M, Frumkin A, Raas-Rothschild A, Glusman G, Lancet D, Bach G. 2000. Identification of the gene causing mucolipidosis type IV. Nat Genet 26: 118-123.

Bar-Peled L, Schweitzer LD, Zoncu R, Sabatini DM. 2012. Ragulator is a GEF for the Rag GTPases that signal amino acid levels to mTORC1. Cell 150: 1196-1208.

Bassi MT, Manzoni M, Monti E, Pizzo MT, Ballabio A, Borsani G. 2000. Cloning of the gene encoding a novel integral membrane protein, mucolipidin - and identification of the two major founder mutations causing mucolipidosis type IV. Am J Hum Genet 67: 1110-1120.

Cang C, Zhou Y, Navarro B, Seo YJ, Aranda K, Shi L, Battaglia-Hsu S, Nissim I, Clapham DE, Ren D. 2013. mTOR regulates lysosomal ATP-sensitive two-pore $\mathrm{Na}^{+}$channels to adapt to metabolic state. Cell 152: 778-790.

Chieregatti E, Meldolesi J. 2005. Regulated exocytosis: New organelles for non-secretory purposes. Nat Rev Mol Cell Biol 6: 181-187.

Coen K, Flannagan RS, Baron S, Carraro-Lacroix LR, Wang D, Vermeire W, Michiels C, Munck S, Baert V, Sugita S, et al. 2012. Lysosomal calcium homeostasis defects, not proton pump defects, cause endo-lysosomal dysfunction in PSEN-deficient cells. J Cell Biol 198: 23-35.

Conner SD, Schmid SL. 2003. Regulated portals of entry into the cell. Nature 422: 37-44.

Cox TM, Cachon-Gonzalez MB. 2012. The cellular pathology of lysosomal diseases. J Pathol 226: 241-254.

Decressac M, Mattsson B, Weikop P, Lundblad M, Jakobsson J, Bjorklund A. 2013. TFEB-mediated autophagy rescues midbrain dopamine neurons from $\alpha$-synuclein toxicity. Proc Natl Acad Sci 110: E1817-E1826.

De Duve C. 2005. The lysosome turns fifty. Nat Cell Biol 7: 847-849.

Dehay B, Bove J, Rodriguez-Muela N, Perier C, Recasens A, Boya P, Vila M. 2010. Pathogenic lysosomal depletion in Parkinson's disease. J Neurosci 30: 12535-12544.

Du H, Duanmu M, Witte D, Grabowski GA. 1998. Targeted disruption of the mouse lysosomal acid lipase gene: Long-term survival with massive cholesteryl ester and triglyceride storage. Hum Mol Genet 7: 1347-1354.

Efeyan A, Zoncu R, Sabatini DM. 2012. Amino acids and mTORC1: From lysosomes to disease. Trends Mol Med 18: $524-533$.

Efeyan A, Zoncu R, Chang S, Gumper I, Snitkin H, Wolfson RL, Kirak O, Sabatini DD, Sabatini DM. 2013. Regulation of mTORC1 by the Rag GTPases is necessary for neonatal autophagy and survival. Nature 493: 679-683.

Ferron M, Settembre C, Shimazu J, Lacombe J, Kato S, Rawlings DJ, Ballabio A, Karsenty G. 2013. A RANKL-PKC $\beta$ TFEB signaling cascade is necessary for lysosomal biogenesis in osteoclasts. Genes Dev 27: 955-969.

Finck BN, Kelly DP. 2006. PGC-1 coactivators: Inducible regulators of energy metabolism in health and disease. J Clin Invest 116: 615-622.

Harris H, Rubinsztein DC. 2012. Control of autophagy as a therapy for neurodegenerative disease. Nat Rev Neurol 8: $108-117$.
He C, Klionsky DJ. 2009. Regulation mechanisms and signaling pathways of autophagy. Annu Rev Genet 43: 6793.

Hemesath TJ, Steingrimsson E, McGill G, Hansen MJ, Vaught J, Hodgkinson CA, Arnheiter H, Copeland NG, Jenkins NA, Fisher DE. 1994. Microphthalmia, a critical factor in melanocyte development, defines a discrete transcription factor family. Genes Dev 8: 2770-2780.

Hershey CL, Fisher DE. 2004. Mitf and Tfe3: Members of a b-HLH-ZIP transcription factor family essential for osteoclast development and function. Bone 34: 689-696.

Ho CY, Alghamdi TA, Botelho RJ. 2012. Phosphatidylinositol-3,5-bisphosphate: No longer the poor PIP2. Traffic 13: $1-8$.

Inoki K, Li Y, Xu T, Guan KL. 2003. Rheb GTPase is a direct target of TSC2 GAP activity and regulates mTOR signaling. Genes Dev 17: 1829-1834.

Jeyakumar M, Dwek RA, Butters TD, Platt FM. 2005. Storage solutions: Treating lysosomal disorders of the brain. Nat Rev Neurosci 6: 713-725.

Kuma A, Hatano M, Matsui M, Yamamoto A, Nakaya H, Yoshimori T, Ohsumi Y, Tokuhisa T, Mizushima N. 2004. The role of autophagy during the early neonatal starvation period. Nature 432: 1032-1036.

Kuroda N, Mikami S, Pan CC, Cohen RJ, Hes O, Michal M, Nagashima Y, Tanaka Y, Inoue K, Shuin T, et al. 2012 Review of renal carcinoma associated with Xp11.2 translocations/TFE3 gene fusions with focus on pathobiological aspect. Histol Histopathol 27: 133-140.

Lapierre LR, De Magalhaes Filho CD, McQuary PR, Chu CC, Visvikis O, Chang JT, Gelino S, Ong B, Davis AE, Irazoqui JE, et al. 2013. The TFEB orthologue HLH-30 regulates autophagy and modulates longevity in Caenorhabditis elegans. Nat Commun 4: 2267.

Laplante M, Sabatini DM. 2012. mTOR signaling in growth control and disease. Cell 149: 274-293.

Lee JH, Yu WH, Kumar A, Lee S, Mohan PS, Peterhoff CM, Wolfe DM, Martinez-Vicente M, Massey AC, Sovak G, et al. 2010. Lysosomal proteolysis and autophagy require presenilin 1 and are disrupted by Alzheimer-related PS1 mutations. Cell 141: 1146-1158.

Levy C, Khaled M, Fisher DE. 2006. MITF: Master regulator of melanocyte development and melanoma oncogene. Trends Mol Med 12: 406-414.

Lieberman AP, Puertollano R, Raben N, Slaugenhaupt S, Walkley SU, Ballabio A. 2012. Autophagy in lysosomal storage disorders. Autophagy 8: 719-730.

Liu B, Du H, Rutkowski R, Gartner A, Wang X. 2012. LAAT1 is the lysosomal lysine/arginine transporter that maintains amino acid homeostasis. Science 337: 351-354.

Logan MR, Odemuyiwa SO, Moqbel R. 2003. Understanding exocytosis in immune and inflammatory cells: The molecular basis of mediator secretion. J Allergy Clin Immunol 111: 923-932; quiz 933.

Luzio JP, Pryor PR, Bright NA. 2007. Lysosomes: Fusion and function. Nat Rev Mol Cell Biol 8: 622-632.

Martina JA, Puertollano R. 2013. Rag GTPases mediate amino acid-dependent recruitment of TFEB and MITF to lysosomes. J Cell Biol 200: 475-491.

Martina JA, Chen Y, Gucek M, Puertollano R. 2012. MTORC1 functions as a transcriptional regulator of au- 
tophagy by preventing nuclear transport of TFEB. $A u$ tophagy 8: 903-914.

Martinez-Vicente M, Talloczy Z, Wong E, Tang G, Koga H, Kaushik S, de Vries R, Arias E, Harris S, Sulzer D, et al. 2010. Cargo recognition failure is responsible for inefficient autophagy in Huntington's disease. Nat Neurosci 13: $567-576$.

Mazzulli JR, Xu YH, Sun Y, Knight AL, McLean PJ, Caldwell GA, Sidransky E, Grabowski GA, Krainc D. 2011. Gaucher disease glucocerebrosidase and $\alpha$-synuclein form a bidirectional pathogenic loop in synucleinopathies. Cell 146: $37-52$.

Medina DL, Fraldi A, Bouche V, Annunziata F, Mansueto G, Spampanato C, Puri C, Pignata A, Martina JA, Sardiello M, et al. 2011. Transcriptional activation of lysosomal exocytosis promotes cellular clearance. Dev Cell 21: 421-430.

Metcalf DJ, Garcia-Arencibia M, Hochfeld WE, Rubinsztein DC. 2010. Autophagy and misfolded proteins in neurodegeneration. Exp Neurol 238: 22-28.

Michell RH, Heath VL, Lemmon MA, Dove SK. 2006. Phosphatidylinositol 3,5-bisphosphate: Metabolism and cellular functions. Trends Biochem Sci 31: 52-63.

Mindell JA. 2012. Lysosomal acidification mechanisms. Annu Rev Physiol 74: 69-86.

Mostov K, Werb Z. 1997. Journey across the osteoclast. Science 276: 219-220.

O’Rourke EJ, Ruvkun G. 2013. MXL-3 and HLH-30 transcriptionally link lipolysis and autophagy to nutrient availability. Nat Cell Biol 15: 668-676.

Palmieri M, Impey S, Kang H, di Ronza A, Pelz C, Sardiello M, Ballabio A. 2011. Characterization of the CLEAR network reveals an integrated control of cellular clearance pathways. Hum Mol Genet 20: 3852-3866.

Pastore N, Blomenkamp K, Annunziata F, Piccolo P, Mithbaokar P, Maria Sepe R, Vetrini F, Palmer D, Ng P, Polishchuk E, et al. 2013. Gene transfer of master autophagy regulator TFEB results in clearance of toxic protein and correction of hepatic disease in $\alpha$-1-anti-trypsin deficiency. EMBO Mol Med 5: 397-412.

Pena-Llopis S, Vega-Rubin-de-Celis S, Schwartz JC, Wolff NC, Tran TA, Zou L, Xie XJ, Corey DR, Brugarolas J. 2011. Regulation of TFEB and V-ATPases by mTORC1. EMBO J 30: 3242-3258.

Price ER, Fisher DE. 2001. Sensorineural deafness and pigmentation genes: Melanocytes and the Mitf transcriptional network. Neuron 30: 15-18.

Rabinowitz JD, White E. 2010. Autophagy and metabolism. Science 330: 1344-1348.

Ramirez A, Heimbach A, Grundemann J, Stiller B, Hampshire D, Cid LP, Goebel I, Mubaidin AF, Wriekat AL, Roeper J, et al. 2006. Hereditary parkinsonism with dementia is caused by mutations in ATP13A2, encoding a lysosomal type 5 P-type ATPase. Nat Genet 38: 11841191.

Reddy A, Caler EV, Andrews NW. 2001. Plasma membrane repair is mediated by $\mathrm{Ca}^{2+}$-regulated exocytosis of lysosomes. Cell 106: 157-169.

Roczniak-Ferguson A, Petit CS, Froehlich F, Qian S, Ky J, Angarola B, Walther TC, Ferguson SM. 2012. The transcription factor TFEB links mTORC1 signaling to tran- scriptional control of lysosome homeostasis. Sci Signal 5: ra42.

Rodriguez-Navarro JA, Cuervo AM. 2012. Dietary lipids and aging compromise chaperone-mediated autophagy by similar mechanisms. Autophagy 8: 1152-1154.

Rodriguez-Navarro JA, Kaushik S, Koga H, Dall'Armi C, Shui G, Wenk MR, Di Paolo G, Cuervo AM. 2012. Inhibitory effect of dietary lipids on chaperone-mediated autophagy. Proc Natl Acad Sci 109: E705-E714.

Rong Y, McPhee CK, Deng S, Huang L, Chen L, Liu M, Tracy K, Baehrecke EH, Yu L, Lenardo MJ. 2011. Spinster is required for autophagic lysosome reformation and mTOR reactivation following starvation. Proc Natl Acad Sci 108: 7826-7831.

Rong Y, Liu M, Ma L, Du W, Zhang H, Tian Y, Cao Z, Li Y, Ren H, Zhang C, et al. 2012. Clathrin and phosphatidylinositol-4,5-bisphosphate regulate autophagic lysosome reformation. Nat Cell Biol 14: 924-934.

Rubinsztein DC, Marino G, Kroemer G. 2011. Autophagy and aging. Cell 146: 682-695.

Rubinsztein DC, Codogno P, Levine B. 2012. Autophagy modulation as a potential therapeutic target for diverse diseases. Nat Rev Drug Discov 11: 709-730.

Saftig P, Klumperman J. 2009. Lysosome biogenesis and lysosomal membrane proteins: Trafficking meets function. Nat Rev Mol Cell Biol 10: 623-635.

Sagne C, Gasnier B. 2008. Molecular physiology and pathophysiology of lysosomal membrane transporters. J Inherit Metab Dis 31: 258-266.

Sancak Y, Peterson TR, Shaul YD, Lindquist RA, Thoreen CC, Bar-Peled L, Sabatini DM. 2008. The Rag GTPases bind raptor and mediate amino acid signaling to mTORC1. Science 320: 1496-1501.

Sancak Y, Bar-Peled L, Zoncu R, Markhard AL, Nada S, Sabatini DM. 2010. Ragulator-Rag complex targets mTORC1 to the lysosomal surface and is necessary for its activation by amino acids. Cell 141: 290-303.

Sardiello M, Palmieri M, di Ronza A, Medina DL, Valenza M, Gennarino VA, Di Malta C, Donaudy F, Embrione V, Polishchuk RS, et al. 2009. A gene network regulating lysosomal biogenesis and function. Science 325: 473477.

Schroder BA, Wrocklage C, Hasilik A, Saftig P. 2010. The proteome of lysosomes. Proteomics 10: 4053-4076.

Schwake M, Schroder B, Saftig P. 2013. Lysosomal membrane proteins and their central role in physiology. Traffic 14: $739-748$.

Settembre C, Annunziata I, Spampanato C, Zarcone D, Cobellis G, Nusco E, Zito E, Tacchetti C, Cosma MP, Ballabio A. 2007. Systemic inflammation and neurodegeneration in a mouse model of multiple sulfatase deficiency. Proc Natl Acad Sci 104: 4506-4511.

Settembre C, Fraldi A, Jahreiss L, Spampanato C, Venturi C, Medina D, de Pablo R, Tacchetti C, Rubinsztein DC, Ballabio A. 2008. A block of autophagy in lysosomal storage disorders. Hum Mol Genet 17: 119-129.

Settembre C, Di Malta C, Polito VA, Garcia Arencibia M, Vetrini F, Erdin S, Erdin SU, Huynh T, Medina D, Colella P, et al. 2011. TFEB links autophagy to lysosomal biogenesis. Science 332: 1429-1433. 
Settembre C, Zoncu R, Medina DL, Vetrini F, Erdin S, Huynh T, Ferron M, Karsenty G, Vellard MC, Facchinetti $\mathrm{V}$, et al. 2012. A lysosome-to-nucleus signalling mechanism senses and regulates the lysosome via mTOR and TFEB. EMBO J 31: 1095-1108.

Settembre C, De Cegli R, Mansueto G, Saha PK, Vetrini F, Visvikis O, Huynh T, Carissimo A, Palmer D, Klisch TJ, et al. 2013a. TFEB controls cellular lipid metabolism through a starvation-induced autoregulatory loop. Nat Cell Biol 15: 647-658.

Settembre C, Fraldi A, Medina DL, Ballabio A. 2013b. Signals from the lysosome: A control centre for cellular clearance and energy metabolism. Nat Rev Mol Cell Biol 14: 283-296.

Shachar T, Lo Bianco C, Recchia A, Wiessner C, RaasRothschild A, Futerman AH. 2011. Lysosomal storage disorders and Parkinson's disease: Gaucher disease and beyond. Mov Disord 26: 1593-1604.

Shen D, Wang X, Li X, Zhang X, Yao Z, Dibble S, Dong XP, Yu T, Lieberman AP, Showalter HD, et al. 2012. Lipid storage disorders block lysosomal trafficking by inhibit ing a TRP channel and lysosomal calcium release. Nat Commun 3: 731 .

Singh R, Cuervo AM. 2011. Autophagy in the cellular energetic balance. Cell Metab 13: 495-504.

Singh R, Kaushik S, Wang Y, Xiang Y, Novak I, Komatsu M, Tanaka K, Cuervo AM, Czaja MJ. 2009. Autophagy regulates lipid metabolism. Nature 458: 1131-1135.

Skibinski G, Parkinson NJ, Brown JM, Chakrabarti L, Lloyd SL, Hummerich H, Nielsen JE, Hodges JR, Spillantini MG, Thusgaard T, et al. 2005. Mutations in the endosomal ESCRTIII-complex subunit CHMP2B in frontotemporal dementia. Nat Genet 37: 806-808.

Sleat DE, Sun P, Wiseman JA, Huang L, El-Banna M, Zheng H, Moore DF, Lobel P. 2013. Extending the mannose 6phosphate glycoproteome by high resolution/accuracy mass spectrometry analysis of control and acid phosphatase 5-deficient mice. Mol Cell Proteomics 12: 1806-1817.

Sorrentino NC, D’Orsi L, Sambri I, Nusco E, Monaco C, Spampanato C, Polishchuk E, Saccone P, De Leonibus E, Ballabio A, et al. 2013. A highly secreted sulphamidase engineered to cross the blood-brain barrier corrects brain lesions of mice with mucopolysaccharidoses type IIIA. EMBO Mol Med 5: 675-690.

Spampanato C, Feeney E, Li L, Cardone M, Lim JA, Annunziata F, Zare H, Polishchuk R, Puertollano R, Parenti G, et al. 2013. Transcription factor EB (TFEB) is a new therapeutic target for Pompe disease. EMBO Mol Med 5: 691-706.

Sridhar S, Patel B, Aphkhazava D, Macian F, Santambrogio L, Shields D, Cuervo AM. 2013. The lipid kinase PI4KIII $\beta$ preserves lysosomal identity. EMBO J 32: 324-339.

Steingrimsson E, Tessarollo L, Reid SW, Jenkins NA, Copeland NG. 1998. The bHLH-Zip transcription factor Tfeb is essential for placental vascularization. Development 125: $4607-4616$.

Steingrimsson E, Tessarollo L, Pathak B, Hou L, Arnheiter H, Copeland NG, Jenkins NA. 2002. Mitf and Tfe3, two members of the Mitf-Tfe family of bHLH-Zip transcription factors, have important but functionally redundant roles in osteoclast development. Proc Natl Acad Sci 99: 4477-4482.

Steingrimsson E, Copeland NG, Jenkins NA. 2004. Melanocytes and the microphthalmia transcription factor network. Annu Rev Genet 38: 365-411.

Sun B, Zhou Y, Halabisky B, Lo I, Cho SH, Mueller-Steiner S, Devidze N, Wang X, Grubb A, Gan L. 2008. Cystatin Ccathepsin $B$ axis regulates amyloid $\beta$ levels and associated neuronal deficits in an animal model of Alzheimer's disease. Neuron 60: 247-257.

Tee AR, Manning BD, Roux PP, Cantley LC, Blenis J. 2003. Tuberous sclerosis complex gene products, Tuberin and Hamartin, control mTOR signaling by acting as a GTPase-activating protein complex toward Rheb. Curr Biol 13: 1259-1268.

Thurston TL, Wandel MP, von Muhlinen N, Foeglein A, Randow F. 2012. Galectin 8 targets damaged vesicles for autophagy to defend cells against bacterial invasion. Nature 482: 414-418.

Tsunemi T, Ashe TD, Morrison BE, Soriano KR, Au J, Roque RA, Lazarowski ER, Damian VA, Masliah E, La Spada AR. 2012. PGC- $1 \alpha$ rescues Huntington's disease proteotoxicity by preventing oxidative stress and promoting TFEB function. Sci Transl Med 4: 142ra197.

Verhoeven K, De Jonghe P, Coen K, Verpoorten N, AuerGrumbach M, Kwon JM, FitzPatrick D, Schmedding E, De Vriendt E, Jacobs A, et al. 2003. Mutations in the small GTPase late endosomal protein RAB7 cause CharcotMarie-Tooth type 2B neuropathy. Am J Hum Genet 72: $722-727$.

Watanabe A, Takeda K, Ploplis B, Tachibana M. 1998. Epistatic relationship between Waardenburg syndrome genes MITF and PAX3. Nat Genet 18: 283-286.

Winslow AR, Chen CW, Corrochano S, Acevedo-Arozena A, Gordon DE, Peden AA, Lichtenberg M, Menzies FM, Ravikumar B, Imarisio S, et al. 2010. $\alpha$-Synuclein impairs macroautophagy: Implications for Parkinson's disease. J Cell Biol 190: 1023-1037.

Woloszynek JC, Coleman T, Semenkovich CF, Sands MS. 2007. Lysosomal dysfunction results in altered energy balance. J Biol Chem 282: 35765-35771.

Wong E, Cuervo AM. 2010. Autophagy gone awry in neurodegenerative diseases. Nat Neurosci 13: 805-811.

Yang L, Li P, Fu S, Calay ES, Hotamisligil GS. 2010. Defective hepatic autophagy in obesity promotes ER stress and causes insulin resistance. Cell Metab 11: 467-478.

Zimprich A, Benet-Pages A, Struhal W, Graf E, Eck SH, Offman MN, Haubenberger D, Spielberger S, Schulte EC, Lichtner P, et al. 2011. A mutation in VPS35, encoding a subunit of the retromer complex, causes late-onset Parkinson disease. Am J Hum Genet 89: 168-175.

Zoncu R, Bar-Peled L, Efeyan A, Wang S, Sancak Y, Sabatini DM. 2011. mTORC1 senses lysosomal amino acids through an inside-out mechanism that requires the vacuolar $\mathrm{H}^{+}$-ATPase. Science 334: 678-683. 


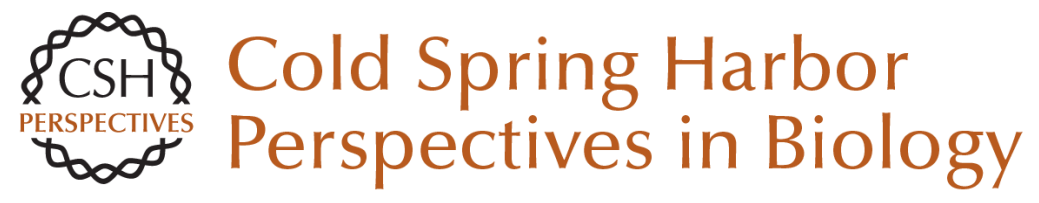

\section{Lysosomal Adaptation: How the Lysosome Responds to External Cues}

Carmine Settembre and Andrea Ballabio

Cold Spring Harb Perspect Biol 2014; doi: 10.1101/cshperspect.a016907 originally published online May 5,2014

\section{Subject Collection Endocytosis}

Endocytosis: Past, Present, and Future Sandra L. Schmid, Alexander Sorkin and Marino Zerial

Rab Proteins and the Compartmentalization of the Endosomal System Angela Wandinger-Ness and Marino Zerial

Cargo Sorting in the Endocytic Pathway: A Key Regulator of Cell Polarity and Tissue Dynamics Suzanne Eaton and Fernando Martin-Belmonte

Unconventional Functions for Clathrin, ESCRTs, and Other Endocytic Regulators in the

Cytoskeleton, Cell Cycle, Nucleus, and Beyond:

Links to Human Disease Frances M. Brodsky, R. Thomas Sosa, Joel A. Ybe, et al.

Endocytosis of Viruses and Bacteria Pascale Cossart and Ari Helenius

Lysosomal Adaptation: How the Lysosome

Responds to External Cues Carmine Settembre and Andrea Ballabio

Reciprocal Regulation of Endocytosis and Metabolism

Costin N. Antonescu, Timothy E. McGraw and Amira Klip

Endocytosis and Autophagy: Exploitation or Cooperation?

Sharon A. Tooze, Adi Abada and Zvulun Elazar
Imaging and Modeling the Dynamics of

Clathrin-Mediated Endocytosis

Marcel Mettlen and Gaudenz Danuser

Endocytic Accessory Factors and Regulation of

Clathrin-Mediated Endocytosis

Christien J. Merrifield and Marko Kaksonen

The Complex Ultrastructure of the Endolysosomal

System

Judith Klumperman and Graça Raposo

The Biogenesis of Lysosomes and

Lysosome-Related Organelles

J. Paul Luzio, Yvonne Hackmann, Nele M.G.

Dieckmann, et al.

Endocytosis, Signaling, and Beyond

Pier Paolo Di Fiore and Mark von Zastrow

Clathrin-Independent Pathways of Endocytosis Satyajit Mayor, Robert G. Parton and Julie G. Donaldson

The Role of Endocytosis during Morphogenetic Signaling Marcos Gonzalez-Gaitan and Frank Jülicher

Role of Endosomes and Lysosomes in Human Disease Frederick R. Maxfield

For additional articles in this collection, see http://cshperspectives.cshlp.org/cgi/collection/

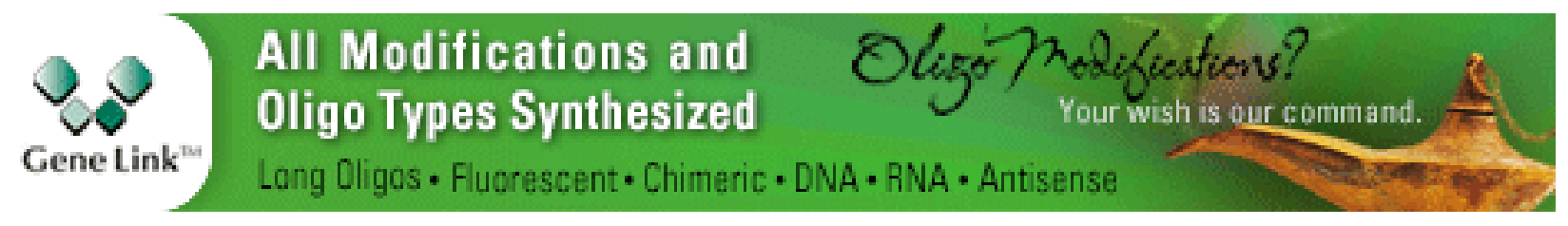


For additional articles in this collection, see http://cshperspectives.cshlp.org/cgi/collection/

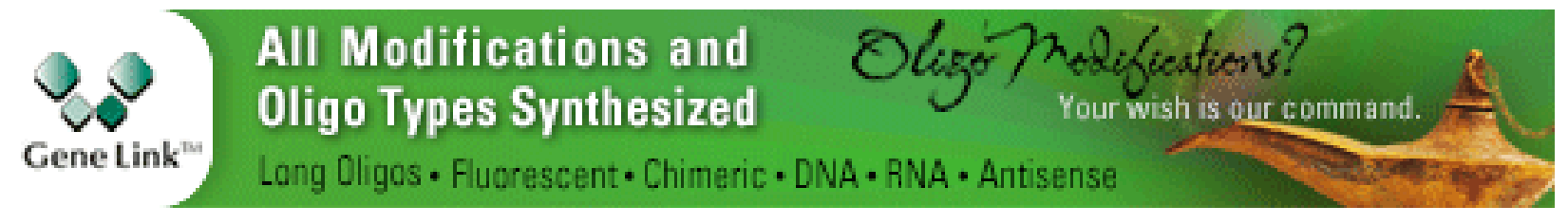

Copyright @ 2014 Cold Spring Harbor Laboratory Press; all rights reserved 